\title{
Predatory and competitive interaction in Anopheles gambiae sensu lato larval breeding habitats in selected villages of central Uganda
}

\author{
Hudson Onen ${ }^{1,2,3^{*}} \mathbb{D}$, Robinson Odong ${ }^{1}$, Moses Chemurot ${ }^{1}$, Frédéric Tripet ${ }^{3^{*}}$ and Jonathan K. Kayondo ${ }^{2}$
}

\begin{abstract}
Background: Malaria is often persistent in communities surrounded by mosquito breeding habitats. Anopheles gambiae sensu lato exploit a variety of aquatic habitats, but the biotic determinants of its preferences are poorly understood. This study aimed to identify and quantify macroinvertebrates in different habitat types with determined water physico-chemical parameters to establish those preferred by An. gambiae s.I. larvae as well as their predators and competitors.

Methods: A field survey was conducted in Kibuye and Kayonjo villages located in the vicinity of the River Sezibwa, north-eastern Uganda to identify Anopheline larval habitats shared by aquatic insects. Habitats were geo-recorded and as streams, ponds, temporary pools and roadside ditches. From October to December 2017, random microhabitats/quadrats were selected from each habitat type, their water physico-chemical parameters (electrical conductivity, total dissolved solids, temperature and $\mathrm{pH}$ ) were measured, and they were sampled for macroinvertebrates using standard dippers. All collected arthropod macroinvertebrates were then morphologically identified to family level and enumerated.

Results: Principal component analysis showed that the four larval habitat types were characterized by distinct physico-chemical parameter profiles. Ponds and streams had the highest number and diversity of macroinvertebrate insect taxa and sustained few An. gambiae s.l. larvae. Anopheles gambiae s.l. were more common in roadside ditches and particularly abundant in temporary pools which it commonly shared with Dytiscidae (predaceous diving beetles) and Culex spp. Cluster correlation analysis conducted on the abundance of these taxa within quadrats suggested that An. gambiae s.l. and Dytiscidae have the most similar patterns of microhabitat use, followed by Cybaeidae (water spiders). Whilst Culex spp. co-occurred with An. gambiae s.l. in some habitats, there was only partial niche overlap and no clear evidence of competition between the two mosquito taxa.
\end{abstract}

Conclusions: Ponds and streams are habitats that host the largest diversity and abundance of aquatic insect taxa. Anopheles gambiae s.l. larvae distinctively preferred temporary pools and roadside ditches, where they were exposed

\footnotetext{
*Correspondence: honen@cns.mak.ac.ug; f.tripet@keele.c.uk; f.tripet@keele.

ac.uk

${ }^{1}$ Department of Zoology, Entomology and Fisheries Sciences, College

of Natural Sciences, School of Biosciences, Makerere University, PO

Box 7062, Kampala, Uganda

${ }^{3}$ Centre for Applied Entomology and Parasitology, School of Life

Sciences, Keele University, Keele, SFD ST5 5BG, UK

Full list of author information is available at the end of the article
}

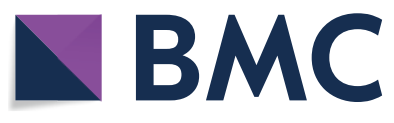

(C) The Author(s) 2021. Open Access This article is licensed under a Creative Commons Attribution 4.0 International License, which permits use, sharing, adaptation, distribution and reproduction in any medium or format, as long as you give appropriate credit to the original author(s) and the source, provide a link to the Creative Commons licence, and indicate if changes were made. The images or other third party material in this article are included in the article's Creative Commons licence, unless indicated otherwise in a credit line to the material. If material is not included in the article's Creative Commons licence and your intended use is not permitted by statutory regulation or exceeds the permitted use, you will need to obtain permission directly from the copyright holder. To view a copy of this licence, visit http://creativecommons.org/licenses/by/4.0/. The Creative Commons Public Domain Dedication waiver (http://creativeco mmons.org/publicdomain/zero/1.0/) applies to the data made available in this article, unless otherwise stated in a credit line to the data. 
to few predators and no apparent competition by Culex spp. Further studies should aim to test the impact of Dytiscidae and Cybaeidae on An. gambiae s.l. dynamics experimentally.

Keywords: Aquatic insects, An. gambiae s.l. competition, Habitat types, Macroinvertebrates, Predation, Niche overlap

\section{Background}

Sub-Saharan African countries account for approximately $90 \%$ of the global malaria cases and deaths [1]. Factors responsible for the persistence and prevalence of malaria in sub-Saharan Africa include the availability of human hosts and favourable conditions for mosquito vector populations, including high temperature, humidity, rainfall and an abundance of aquatic breeding habitats [2,3]. Since the implementation of Roll Back Malaria, the widespread use of insecticide-treated nets (ITNs) and indoor residual spraying (IRS) has played a significant role in reducing mortality and morbidity in malaria-endemic regions [4]. However, the intervention's effectiveness is threatened by the fast spread of resistance to most chemical insecticides available for public health, change in vector species composition and a shift in vector biting behaviour [5]. Outdoor biting mosquitoes are responsible for residual malaria transmission in many parts of subSaharan Africa and pose new challenges, as they are not sufficiently controlled using conventional tools [6].

Therefore, there is an urgent need to improve larval source management (LSM) by considering aquatic insect predators as a scalable tool for integrated vector management (IVM) programs to reduce malaria vector populations [7-9]. To be successful, IVM programs using LSM would benefit from in-depth knowledge of the mosquito larval ecology and a better understanding of the trophic interactions in larval habitats. This could prioritize larval control efforts focusing on habitats that sustain the highest densities of anopheline larvae while protecting habitats rich in natural predators. A better understanding of prey-predator spatio-temporal dynamics could also lead to discovering and adding new biocontrol tools in the fight against malaria. Finally, assessing larval habitat preferences, the extent of niche overlap and possible competitive interactions between mosquito taxa is also relevant to predicting possible changes in mosquito communities and disease transmission in response to vector control interventions. It can also help understand the possible consequences of suppressing the malaria mosquito, Anopheles gambiae sensu lato, on aquatic predators and competitors in ecosystems [10].

Across many regions of Africa, mosquito species within the An. gambiae s.l. complex are responsible for the majority of malaria transmission [11]. The species in the complex are An. amharicus, An. arabiensis, An. bwambae, An. coluzzii, An. gambiae sensu stricto, An. melas, An. merus, An. quadriannulatus and An. fontenillei [12-14]. Their respective spatio-temporal distribution and ecological niches are largely determined by patterns of temperatures, rainfall and physico-chemical parameters of their preferred breeding sites $[2,15]$. For instance, An. bwambae breeds in brackish geothermal spring water [16], while An. melas and An. merus are often associated with saline waters [17]. Among the freshwater-adapted species, An. gambiae s.s. and An. arabiensis prefer temporary sunlit habitats such as ground puddles, tire tracks and hoof prints, while An. coluzzii are mainly found in more permanent and sometimes larger artificial water bodies such as rice fields $[18,19]$.

The different breeding habitats of the An. gambiae s.l. species complex varies in the predator and competitor taxa they support [20]. Compared to temporary habitats, permanent breeding habitats tend to support higher densities of predator and competitor taxa [21]. Predation on larvae by aquatic insect predators affects larval development, impacts the adult sex ratio at emergence and subsequently influences the adult life-history traits such as body size, fecundity and longevity [22, 23]. The presence of predators and competitors in aquatic larval habitats lowers their chances of being chosen as oviposition sites by female $A n$. gambiae s.s. [24, 25]. Such adaptive responses would, therefore, ensure that females lay eggs in habitats that maximize their offspring's survival [26].

Anopheles coluzzii is restricted to West and Central Africa; hence, in East African countries such as Kenya [27, 28], Uganda [29] and Tanzania [30, 31], An. gambiae s.s. and An. arabiensis are the dominant species of the An. gambiae species complex and are present in various lowland and highland breeding habitats [32]. On the other hand, An. merus is found in Kenya and Tanzania's coastal areas [33, 34]. As in West Africa, the larval breeding habitats of An. gambiae s.s. and An. arabiensis are also inhabited by various aquatic insect predators and larvae from other mosquito genera such as Culex and Aedes [35]. Larvae are sometimes also found together with those from the An. funestus complex, although the latter tend to prefer small spring-fed pools, mediumsized natural ponds and slow-moving waters along river tributaries [36]. Depending on breeding habitats and their physico-chemical parameters, other less common mosquito species can be found together with $A n$. gambiae s.l. For example, in Northern Tanzania, other anophelines and Aedes spp. are sometimes found [20]. 
In north-eastern Uganda and the Lake Victoria Basin (LVB) region, some villages have a high abundance of $A n$. gambiae s.s. in various commonly occurring breeding habitats, including streams and standing waters [37, 38]. Although some regions in East Africa have similar ecologies, the communities of aquatic predators and competitors of $A n$. gambiae s.l. are poorly known. This study attempted to fill this gap by determining the diversity and abundance of potential predators and larval competitors of An. gambiae s.l. as well as their associations in ponds, roadside ditches, temporary pools and streams with the determined water physico-chemical parameters in Kibuye and Kayonjo villages located near River Sezibwa in north-eastern Uganda. These findings were important for assessing the relevance of potential predatory and competitive interactions between aquatic macroinvertebrates and larvae of the malaria vectors. This information could inform vector control strategies targeting larval habitats through physical or biocontrol approaches and lead to novel biocontrol approaches to complement current malaria vector control programs.

\section{Methods}

\section{Study area}

This study was conducted in Kibuye and Kayonjo villages situated along the River Sezibwa of central Uganda from October to December 2017. Kibuye is located on the western side of the riverbank in the Mukono district, while Kayonjo is on the Kayunga district's eastern bank (Fig. 1). Kibuye and Kayonjo are approximately
$33 \mathrm{~km}$ apart, 68 and $81 \mathrm{~km}$ from Kampala (Uganda's capital city), respectively. Mukono lies within $0^{\circ} 21^{\prime} 17.99^{\prime \prime}$ $\mathrm{N}, 32^{\circ} 45^{\prime} 07.57^{\prime \prime} \mathrm{E}$, with a total human population of 596,804 on $1875.1 \mathrm{~km}^{2}$ of land cover [39]. With a total human population of 294,613 on $1810 \mathrm{~km}^{2}$ of land cover, Kayunga lies within $0^{\circ} 45^{\prime} 59.29^{\prime \prime} \mathrm{N}, 32^{\circ} 59^{\prime} 00.47^{\prime \prime}$ E. Both districts are predominantly covered by savannah vegetation [40] and experience two rainy seasons in a year (wet seasons: March-May, September-December; dry seasons: June-October, December-February). The average annual temperature in Kayunga and Mukono district is $21.5^{\circ} \mathrm{C}$ [41]. The main economic activities in the study area are fishing and subsistence agriculture.

\section{Characterization of mosquito breeding habitats}

Field surveys were conducted in Kibuye and Kayonjo villages in July 2017 to identify the potential breeding habitats of An. gambiae s.l. and associated macroinvertebrates [35]. Geographical coordinates of habitats were recorded using a Global Positioning System (Shenzhen Pengjin Technology Co., Ltd., Shenzhen, China) receiver, and their average surface areas $\left(\mathrm{m}^{2}\right)$ were estimated. Based on the survey results, four habitat types were identified in each village and categorized as follows: streams (i.e., naturally slow-running water bodies with diversions of stagnant water from the mainstream which may not dry off in the absence of rainfall); ponds (non-flowing water collected in artificial pools that may not dry off within 6 months in the absence of rainfall); temporary pools (pools of water collected often within rocks and other

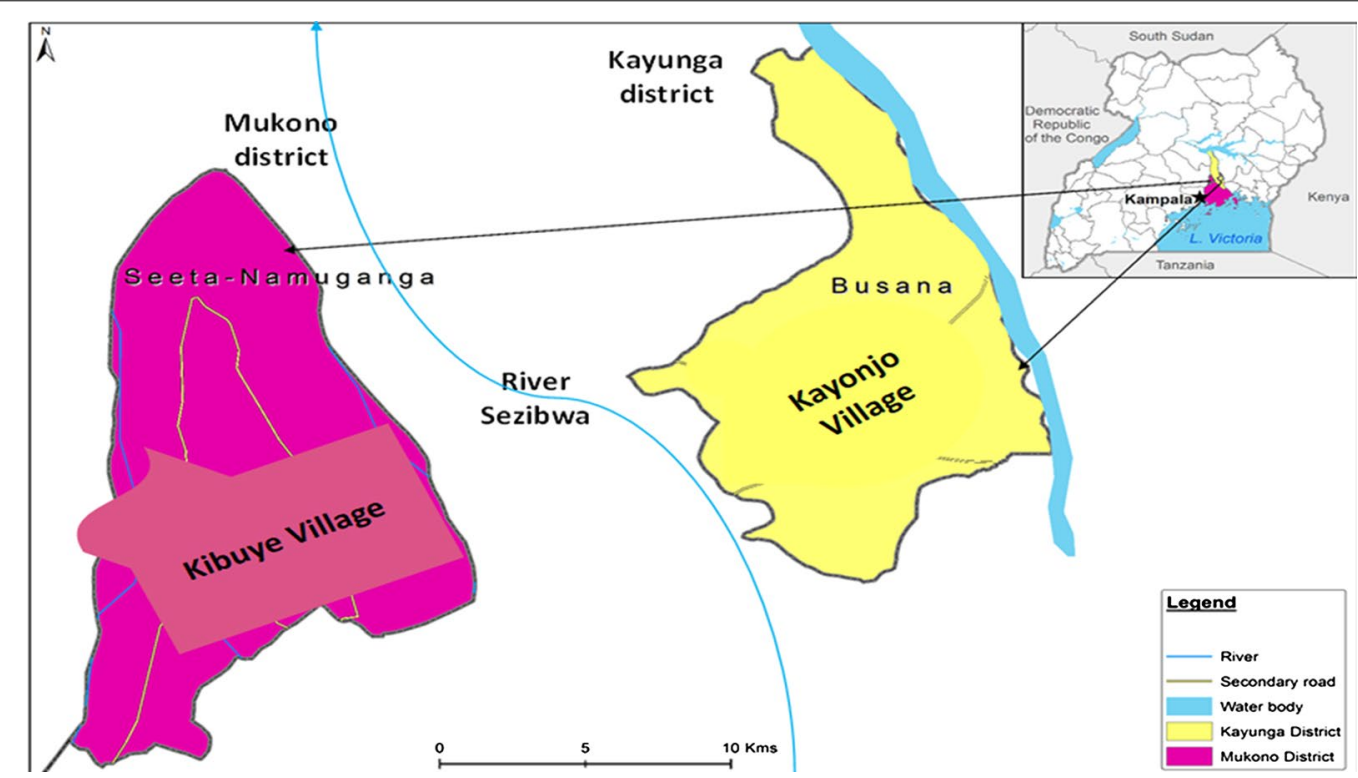

Fig. 1 Location of the study sites in Mukono and Kayunga districts, Uganda. Source: Google Earth and field survey coordinates. The map was created using QGIS and publicly available shapefiles from QGIS website (https://qgis.org/en/site/) 
brick pits which could persist for at least a month in the absence of rainfall); and roadside ditches (pools of water often collected along the road pavement that could persist for at least 2 weeks in the absence of rainfall) (Fig. 2).

\section{Determination of water physico-chemical parameters}

From October to December 2017 and for each category of habitat type, four larval habitats in each village were sampled monthly over 4 days of fieldwork (32 independent habitats surveyed). A total of eight $1 \times 1 \mathrm{~m}$ quadrats were randomly selected from each habitat type, totaling 256 quadrants. Therefore, a total of 768 quadrats were surveyed over the 3-month study.

For each quadrat sampled, the electrical conductivity (EC) $(\mu \mathrm{S} / \mathrm{cm})$, total dissolved solids (TDS) $(\mathrm{mg} / \mathrm{l}), \mathrm{pH}$ and temperature $\left({ }^{\circ} \mathrm{C}\right)$ were measured by dipping a calibrated "three-in-one" Netutal pocket pen-type TDS meter probe (Shanghai Hello Pure Water Treatment Technology Co., Ltd., Shanghai, China) and ATC [automatic temperature compensation] digital $\mathrm{pH}$ meter (Shanghai Hello Pure Water Treatment Technology Co., Ltd., Shanghai, China) in water. Measurements were conducted in situ in the morning (10:00-11:00) and afternoon (13:00-14:00), and averaged readings were recorded.

\section{Sampling and identification of predator and competitor macroinvertebrates}

Each randomly picked quadrat for An. gambiae s.l. larvae and other aquatic insects was sampled by dipping standard $350 \mathrm{ml}$ dippers (BioQuip Products, Inc., CA, USA) four times per quadrat. Samples collected from each quadrat in the morning and afternoon were combined and sieved using a stainless-steel mesh strainer (Innovative Lab Instruments, New Delhi, India). Sorting of invertebrates was done in the field, and samples were preserved in $5 \mathrm{ml}$ falcon tubes (Fisher Scientific Ltd., UK) containing $80 \%$ ethanol. They were transported to the Entomology laboratory at the Uganda Virus Research Institute (UVRI) in Entebbe and identified by morphological characteristics to family level with the aid of a microscope (Opto-Edu Co., Ltd., Beijing, China) at $\times 40$ eyepiece magnification. The identification of macroinvertebrates was carried out with the use of guides by Gerber and Gabriel [42] and Gill [43], while guides by Hopkins [44] and Rozeboom and Stone [45] were used for the identification of mosquito larvae. The identified individuals were counted.
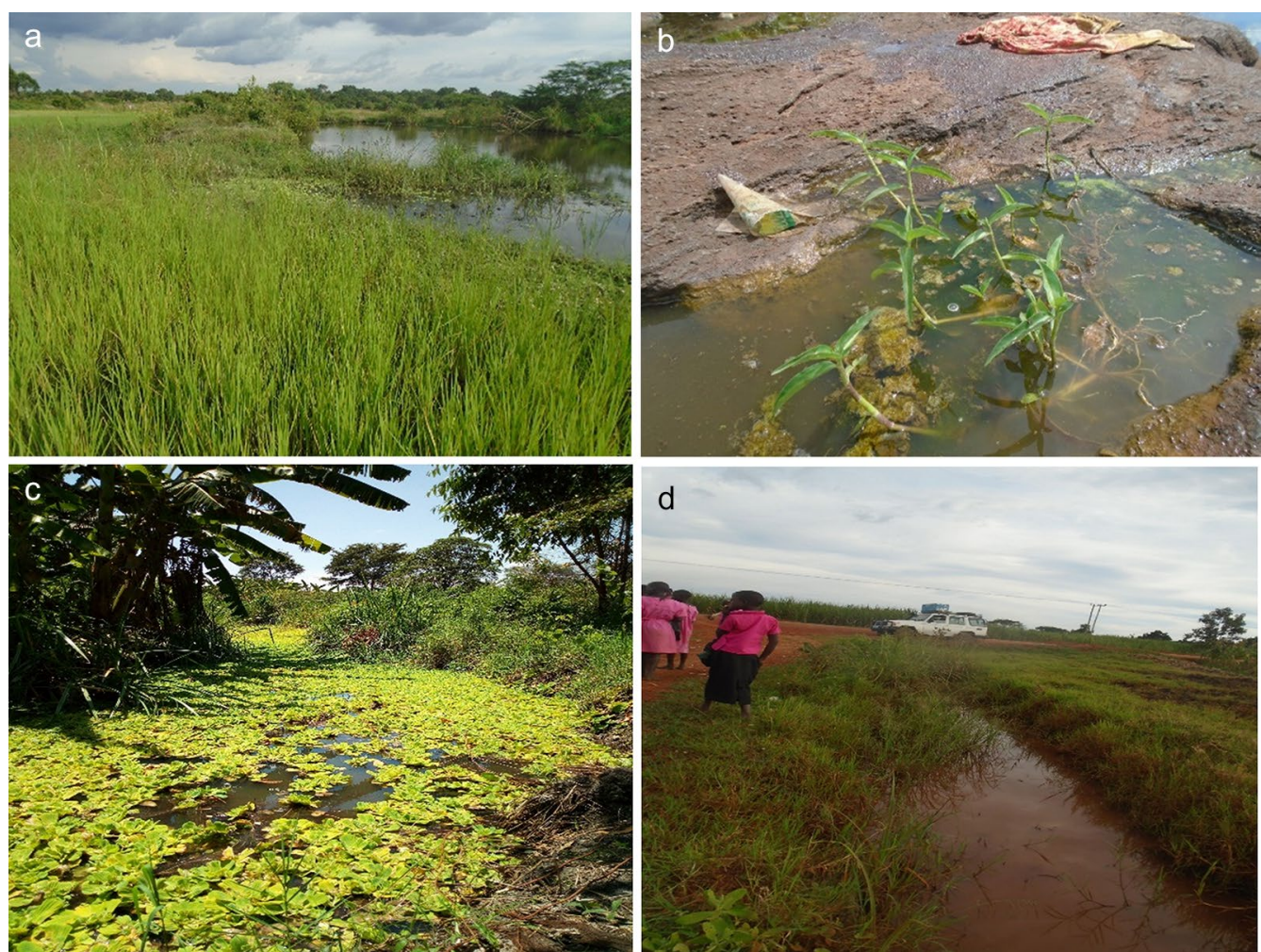

Fig. 2 Stream, temporary pool, pond and roadside ditch mosquito and macroinvertebrate larval habitats $(\mathbf{a}, \mathbf{b}, \mathbf{c}$ and $\mathbf{d})$. Larval habitats where samples were taken from randomly selected quadrats after determination of water physico-chemical parameters 


\section{Data analyses}

\section{Criteria used for identification of the statistical unit}

Particular attention was paid to identifying the unit of analysis appropriate for revealing possible interactions between aquatic insect taxa at the quadrats' microhabitat scale. Water physico-chemical parameters did not vary much between quadrats within a breeding site. This was verified using neighbour-joining clustering analysis based on all the four water physico-chemical parameters (TDS, pH, EC and temperature), which showed that randomly sampled quadrats from the same habitat tended to cluster together (Additional file 1: Figure S1a). Therefore, the mean from all quadrats from each habitat $(n=32)$ was used for all analyses to avoid pseudoreplication.

In contrast, data on aquatic insect taxa presence or absence, abundance and frequency (percentage of quadrats where the taxa were detected) were analysed using each quadrat as a statistical unit $(n=768)$. This was done under the assumption that stream, pond, temporary pool and roadside ditch larval habitats are spatially heterogeneous. Therefore, predatory or competitive interactions between aquatic insect taxa are best examined at the micro spatial scale of the quadrats-i.e., microhabitats within larval habitats. Neighbour-joining clustering based on all aquatic insect taxa's abundance demonstrated that randomly sampled quadrats taken from the same habitat did not cluster together, thereby highlighting the importance of variation within habitats (Additional file 1: Figure S1b).

\section{Statistical analyses}

All data obtained were analysed using JMP version 14 software (SAS Institute, Inc., USA). Data were checked for deviations from normality and heterogeneity, and analyses were conducted using parametric and non-parametric methods as appropriate. The Shannon-Weaver Index $[46,48]$ was used to measure macroinvertebrate diversity across villages, months of collections and habitat types. Multivariate analysis using principal component analysis (PCA) was conducted to highlight differences in water physico-chemical parameter profiles $(\mathrm{pH}, \mathrm{TDS}$, EC and temperature) across habitat types. Spearman's rank correlation test was conducted to examine possible associations between the abundance of $A n$. gambiae s.l. and that of macroinvertebrates across and within the four habitat types. Cluster correlation analysis was used to highlight further similarities in each taxa profile of correlation in abundance with other species, hence overlapping habitat and microhabitat use. Finally, the cluster membership data generated for each taxon and the three habitats most commonly used by An. gambiae s.l. was used for two-way higher-level hierarchical clustering analyses using neighbour-joining (Ward clustering).

\section{Results}

\section{Physico-chemical parameters of aquatic habitat types}

Overall, there was no significant difference in mean temperature, $\mathrm{pH}$, TDS, or EC measured from each larval breeding site in relation to village (Kruskal-Wallis H-test: $\chi^{2}<0.12, d f=1, P>0.736$ in all cases) and month of collections (Kruskal-Wallis H-test: $\chi^{2}<2.73, d f=3, P>0.257$ in all cases). Predictably, clustering analysis showed that measurements taken at different time points or different quadrats from the same breeding site often clustered together (Additional file 1: Figure S1a). Consequently, subsequent analyses were conducted on the mean water physico-chemical parameters values per breeding site across all samples measured over the three months.

Streams, ponds, temporary pools and roadside ditches differed significantly in some of their water physicochemical parameters (temperature, $\mathrm{pH}$, TDS and EC) (Kruskal-Wallis H-test: $\chi^{2}>25.2, \quad d f=3, \quad P<0.001$ for all four parameters). Roadside ditches had a significantly higher temperature than temporary pools, ponds and streams (Dunn pairwise comparisons test: $Z>3.7$, $P<0.013$ in all cases). The same applied to other water physico-chemical parameters such as $\mathrm{pH}$ (Dunn pairwise comparisons test: $Z>3.4, P<0.042$ in all cases), EC (Dunn pairwise comparisons: $Z>3.2$ and $P<0.052$ in all cases) and TDS (Dunn pairwise comparisons test: $Z>3.9$; $P<0.03$ in all cases).

The highest mean temperature was recorded in roadside ditches followed by temporary pools, ponds, and the lowest in streams. The same trends were also recorded with $\mathrm{pH}, \mathrm{EC}$ and TDS. In habitats with lower mean temperatures, such as in streams and ponds, $\mathrm{pH}$ was slightly acidic, but in temporary pools and roadside ditches, which were generally warmer, $\mathrm{pH}$ was alkaline. Furthermore, EC and TDS values were low in streams and ponds but high in temporary pools and roadside ditches

Table 1 Mean and standard deviation of water temperature, conductivity, total dissolved solids and $\mathrm{pH}$ across habitat types

\begin{tabular}{lllll}
\hline Habitat & $\begin{array}{l}\text { Temperature } \\
\left({ }^{\circ} \mathrm{C}\right)\end{array}$ & $\mathrm{EC}(\mathrm{uS} / \mathrm{cm})$ & $\mathrm{TDS}(\mathrm{mg} / \mathrm{l})$ & $\mathrm{pH}$ \\
\hline $\begin{array}{llll}\text { Streams } \\
\text { Ponds }\end{array}$ & $26.3 \pm 0.29$ & $366.5 \pm 35.36$ & $470.9 \pm 28.08$ & $3.8 \pm 0.38$ \\
$\begin{array}{c}\text { Temporary } \\
\text { pools }\end{array}$ & $29.0 \pm 0.15$ & $415.3 \pm 5.46$ & $522.8 \pm 15.44$ & $6.4 \pm 0.72$ \\
$\begin{array}{c}\text { Roadside } \\
\text { ditches }\end{array}$ & $30.8 \pm 0.28$ & $441.3 \pm 13.03$ & $556.6 \pm 33.67$ & $8.1 \pm 0.13$ \\
\hline
\end{tabular}

EC electrical conductivity, TDS total dissolved solids 
(Table 1). All variables were intercorrelated, with $\mathrm{pH}$ and temperature being the most intercorrelated (Spearman correlation test: $\left.r_{(123)}=0.921, P<0.001\right)$, while conductivity and TDS were the least (Spearman: $r_{(123)}=0.608$, $P<0.001)$. PCA showed that physico-chemical parameters had high canonical and significant loadings on the first two components (Bartlett test on eigenvalues: $X^{2}>23.0, P<0.001$ in both cases). All parameters contributed to component 1 (loading value range 0.861-0.963), which explained $84.4 \%$ of the variance. Additionally, conductivity and TDS had a medium positive $(0.475)$ and negative $(-0.406)$ loading on component $2(10.2 \%$ of variance). The resulting PCA scores resulted in distinct clusters for the four aquatic habitats (Fig. 3).

\section{Diversity of competitor and predator insect taxa in aquatic habitats}

A total of 1428 macroinvertebrate specimens were collected from streams, ponds, temporary pools and roadside ditches in Kibuye and Kayonjo villages from October to December 2017. Of the collected specimens, 96 were anopheline mosquito larvae belonging to the An. gambiae s.l. complex, while 1332 were aquatic macroinvertebrates belonging to 14 families, including Culicinae mosquito larvae (Additional file 2: Table S1 and S2).

Overall, ponds and streams had the highest number of macroinvertebrate insect taxa, or taxa richness $(n=14)$, followed by temporary pools $(n=12)$ and roadside ditches $(n=11)$. Diversity (Shannon index) followed a similar pattern. The two villages had very similar profiles in terms of taxa present and diversity and did not differ significantly in median abundance of each taxon (Wilcoxon signed-rank test: $Z=-223.00 ; P=0.180$ ). In addition, the median abundance of taxa for each habitat correlated strongly between the two villages (Spearman rank correlation test: ponds: $R h o=0.934, P=0.001$; streams: $R h o=0.992, \quad P=0.001$; roadside ditches: $R h o=0.600, P=0.023$; and temporary pools: $R h o=0.945$, $P=0.001$ ). Further analyses were therefore performed across the combined data from both villages.

\section{Abundance and frequency of competitors and predator insect taxa and aquatic habitat type}

Overall, the median abundance of macroinvertebrate insect taxa differed significantly between habitat types (Kruskal-Wallis H-test: $\chi^{2}=28.0, d f=3, P<0.001$ ). Ponds and streams supported the highest numbers of aquatic insects (Additional file 2: Table S1 and S2) and did not differ significantly in median abundance (Dunn pairwise comparisons test: $Z=0.51, P=1.00$ ). Roadside ditches and temporary pools supported significantly lower aquatic insect abundance than the other two habitat types (Dunn pairwise comparisons test: $Z>2.7, P<0.032$ in all cases).

Streams and ponds differed in their most abundant taxa and frequency. Few An. gambiae s.l. larvae were collected

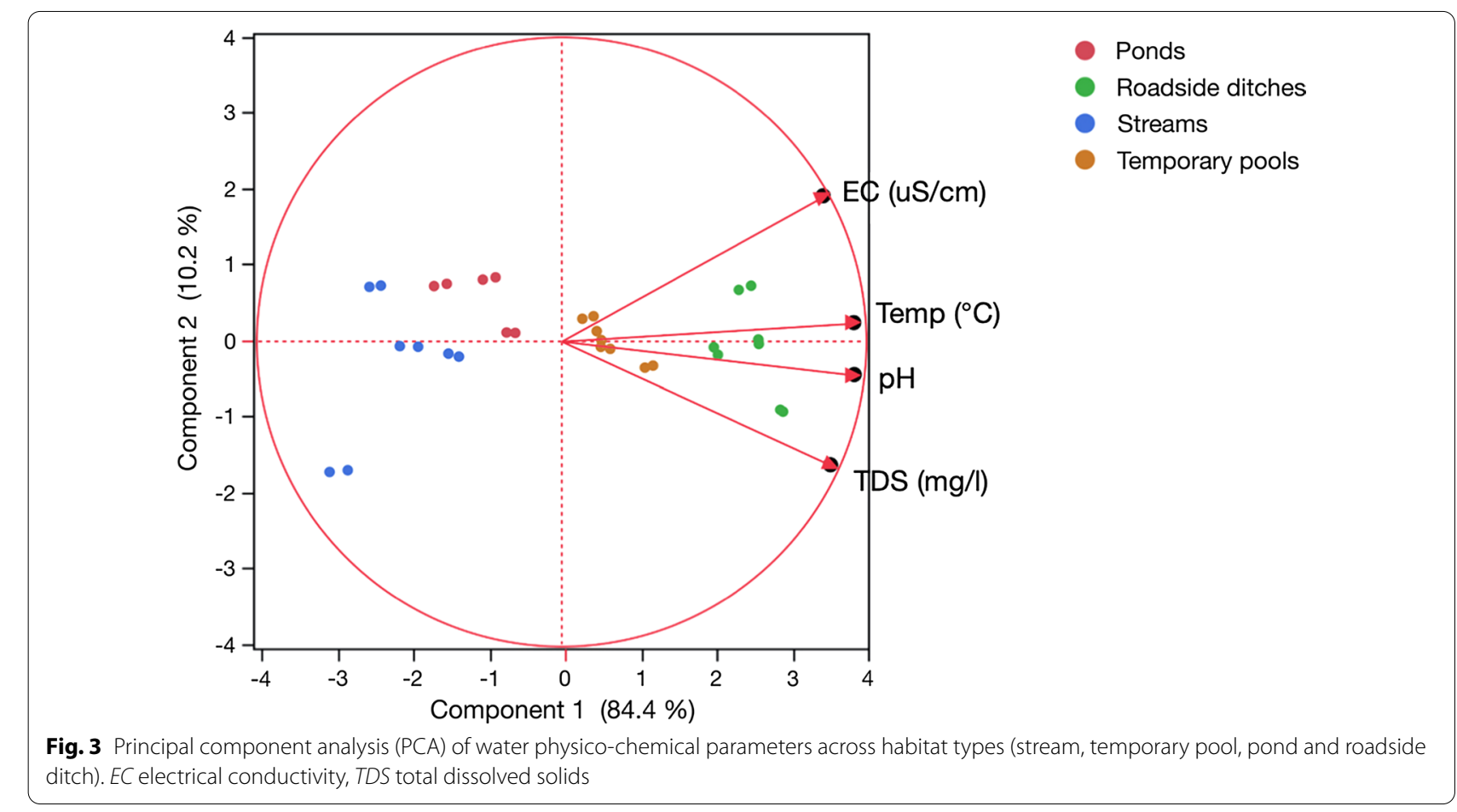


from ponds, and they were present in only $37.5 \%$ of pond quadrats in both villages. They were rare observations from quadrats from streams with less than $1 \%$ frequency in both villages. These habitats differed in the type of aquatic insect communities they supported. For example, ponds had the highest abundance of Dytiscidae which occurred at $100 \%$ frequency in both villages, followed by Notonectidae (backswimmers) which had an average frequency of $99.1 \%$ across both villages. In streams, Baetidae (minnow mayflies) recorded the highest abundance, followed by Coenagrionidae (narrow-winged damselflies) and Aeshnidae (darner dragonflies), with all the taxa occurring at $100 \%$ frequency in both villages. The preferred habitats for An. gambiae s.l. larvae were temporary pools and roadside ditches. They were detected in 99.1 and $75 \%$ of sampled quadrats in Kibuye and Kayonjo villages, respectively, and these habitats were shared with Culex spp. larvae at a frequency between 62.5 and $100 \%$. Dytiscidae were the most abundant predators in these habitats, followed by Notonectidae, Haliplidae (crawling water beetles) and Elmidae (riffle beetles) (Additional file 2: Tables S1, S2 and Fig. 4).

\section{Temporal changes in the abundance of aquatic insect taxa}

The abundance of some aquatic insect taxa in ponds, roadside ditches, streams and temporary pools varied significantly between months of collection (KruskalWallis H-test: $\chi^{2}>6.4, d f=2, P<0.05$ in all cases). In ponds, Gyrinidae (whirligig beetles) and Hydrophilidae (water scavenger beetles) were significantly more abundant during the start and peak of the short rainy season in October and November (Dunn pairwise comparisons test: $Z<-10.8, P<0.001$ in both cases). In contrast, Baetidae was significantly more common in December, the rainy season's end (Dunn pairwise comparisons test: $Z=2.5, P=0.039$ ). In roadside ditches, Aeshnidae, Baetidae, Coenagrionidae and Nepidae (water scorpions) increased in abundance towards the end of the rainy season (Dunn pairwise comparisons test: $Z>2.5, P<0.039$ ).

In streams, $A n$. gambiae s.l. were more abundant in November at the peak of the short rainy season rather than at the start (Dunn pairwise comparisons test: $Z<3.9, P<0.05)$, and the same was true for Hydrophilidae (Dunn pairwise comparisons test: $Z<10.9, P<0.001$ ). However, the collected number of Cybaeidae, Gyrinidae and Haliplidae significantly increased in December, the end of the short rainy season (Dunn pairwise comparisons test: $Z>3.0, P<0.007$ in all cases). In temporary pools, An. gambiae s.l. larvae, Culicidae larvae and Gyrinidae were significantly more abundant in October than in the following months (Dunn pairwise comparisons test: $Z>-3.2, P<0.004$ in all cases) (Fig. 5).

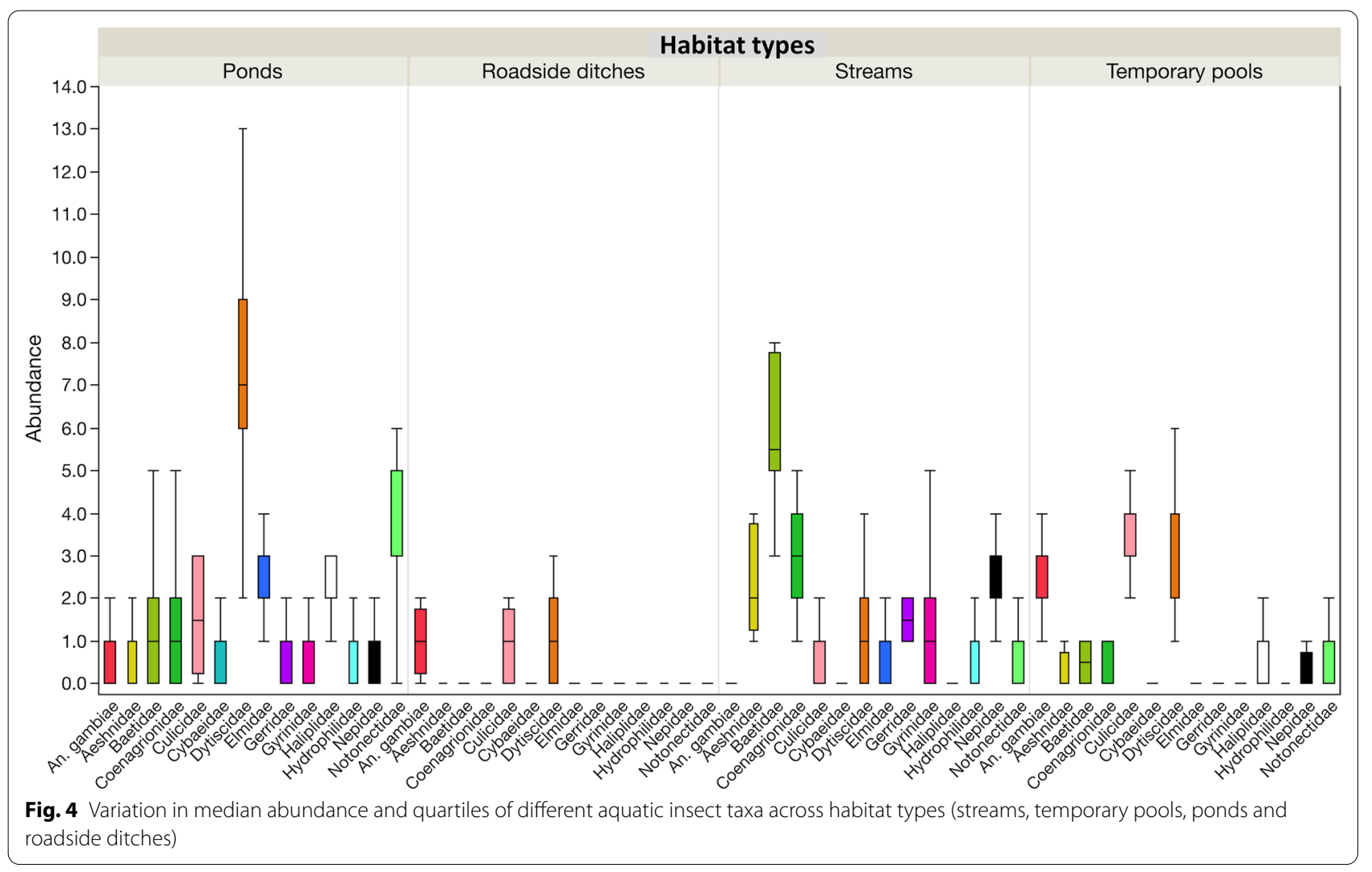




\section{a}
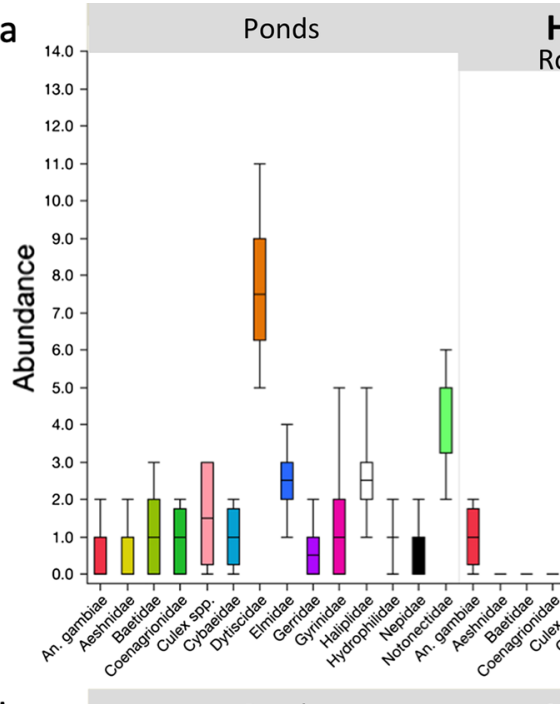

b

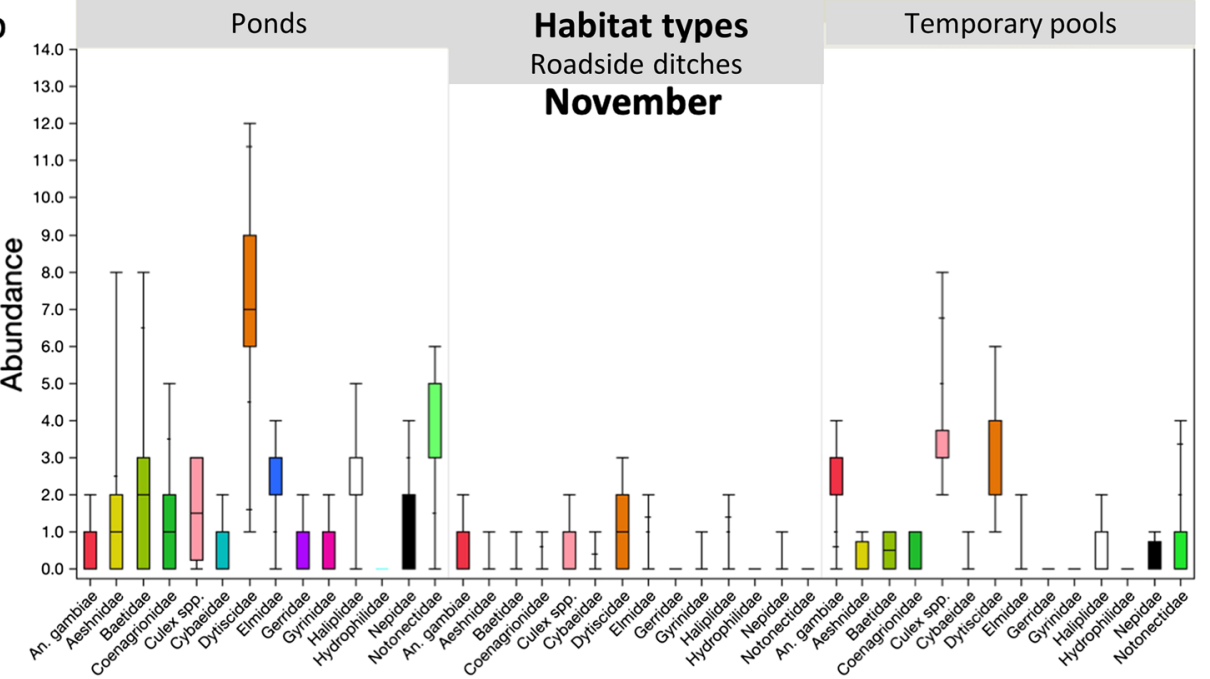

C

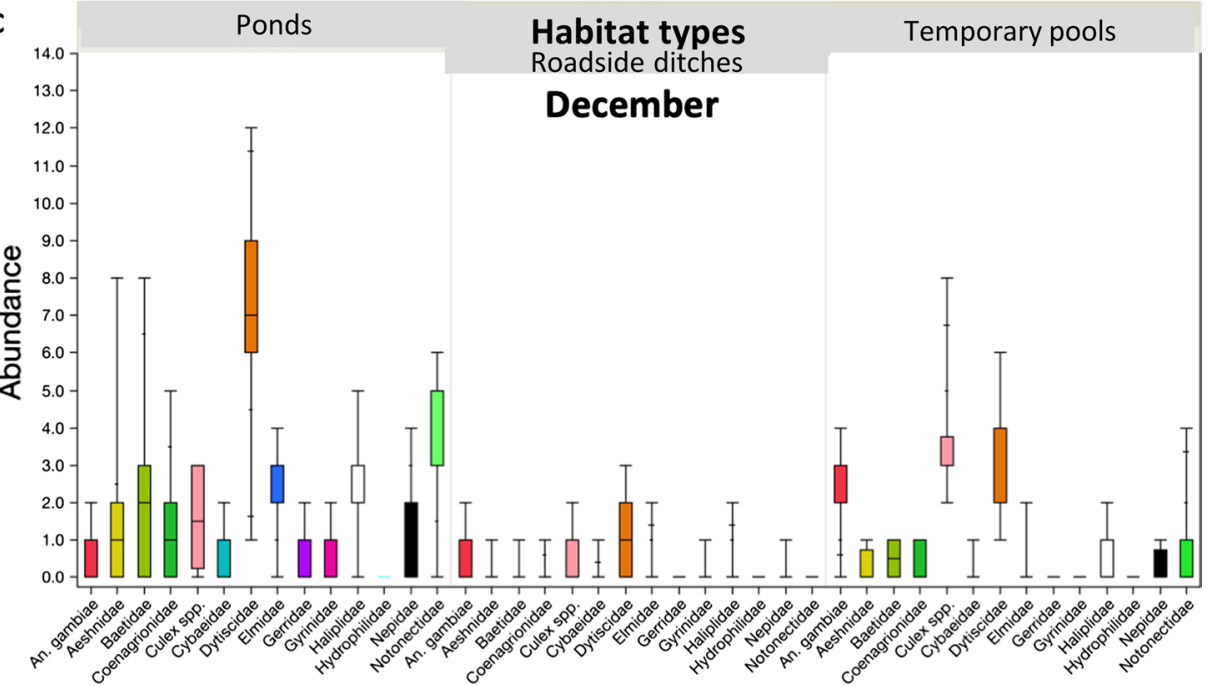

Habitat types Temporary pools

October

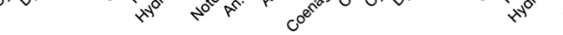


Variation in diversity in relation to habitat type and season The diversity of taxa (Shannon index) varied significantly across habitat types (Kruskal-Wallis H-test: $\left.X^{2}=429.3, d f=3, P<0.001\right)$. On average, the highest diversity was recorded in streams $(1.10,1.10-1.12)$ followed by ponds $(1.11,1.07-1.14)$, temporary pools $(0.99$, $0.93-1.02)$ and roadside ditches $(0.71,0.65-0.76)$ (Additional file 2: Tables S1, S2 and Fig. 6). The diversity of insect taxa increased from November to December in ponds and roadside ditches (Dunn pairwise comparisons test: $Z<7.8, P<0.001$ in both cases), and from October to November in streams (Dunn pairwise comparisons test: $Z=6.5, P<0.001$ ), while in temporary pools, no significant increase was recorded (Wilcoxon rank-sum test: $x^{2}=2.7, d f=2, P=0.263$ ) (Fig. 6).

\section{Association between An. gambiae s.l. larvae, predators and competitors}

Across all habitats there was a moderate positively correlated abundance of An. gambiae s.l. with Culex spp., thus highlighting that both taxa are rare in streams but plentiful in ponds, roadside ditches and temporary pools (Additional file 2: Table S3). There was also a weak but significant positive correlation with Dytiscidae, which is often present with An. gambiae s.l. There was significant abundance of An. gambiae s.l. negatively correlated with all other aquatic predatory taxa that are typically abundant in ponds and streams but not temporary habitats, except Cybaeidae. Clustering correlation analyses across habitats explained $77.3 \%$ of the variation in the data. Four clusters were identified, with a mean proportion of cluster variation explaining $79.1 \%( \pm 5.4 \mathrm{SD})$ and good overall fit illustrated by a low average $1-R^{2}$ ratio $\left[\left(1-R^{2}\right.\right.$ with own cluster $) /\left(1-R^{2}\right.$ with next closest $\left.)\right]$ equal to 0.261 $( \pm 0.069 \mathrm{SD})$ (Fig. 7, Additional file 2: Table S4). Overall, this analysis mirrored the pairwise correlations between taxa and the two mosquito taxa clustered together due to broad similarities in habitat type preference and partial niche overlap.

Next, pairwise correlations between taxa and cluster correlation analyses were performed using the microhabitat (quadrat) data for each habitat type, except for streams, where $A n$. gambiae s.l. was very rarely found. In pond microhabitats, there was a moderate positively correlated abundance of An. gambiae s.l. with Dytiscidae, Coenagrionidae, Cybaeidae, Culicidae, Elmidae and Nepidae. It also correlated negatively with Gerridae (water striders), Haliplidae and Baetidae. The clustering of all

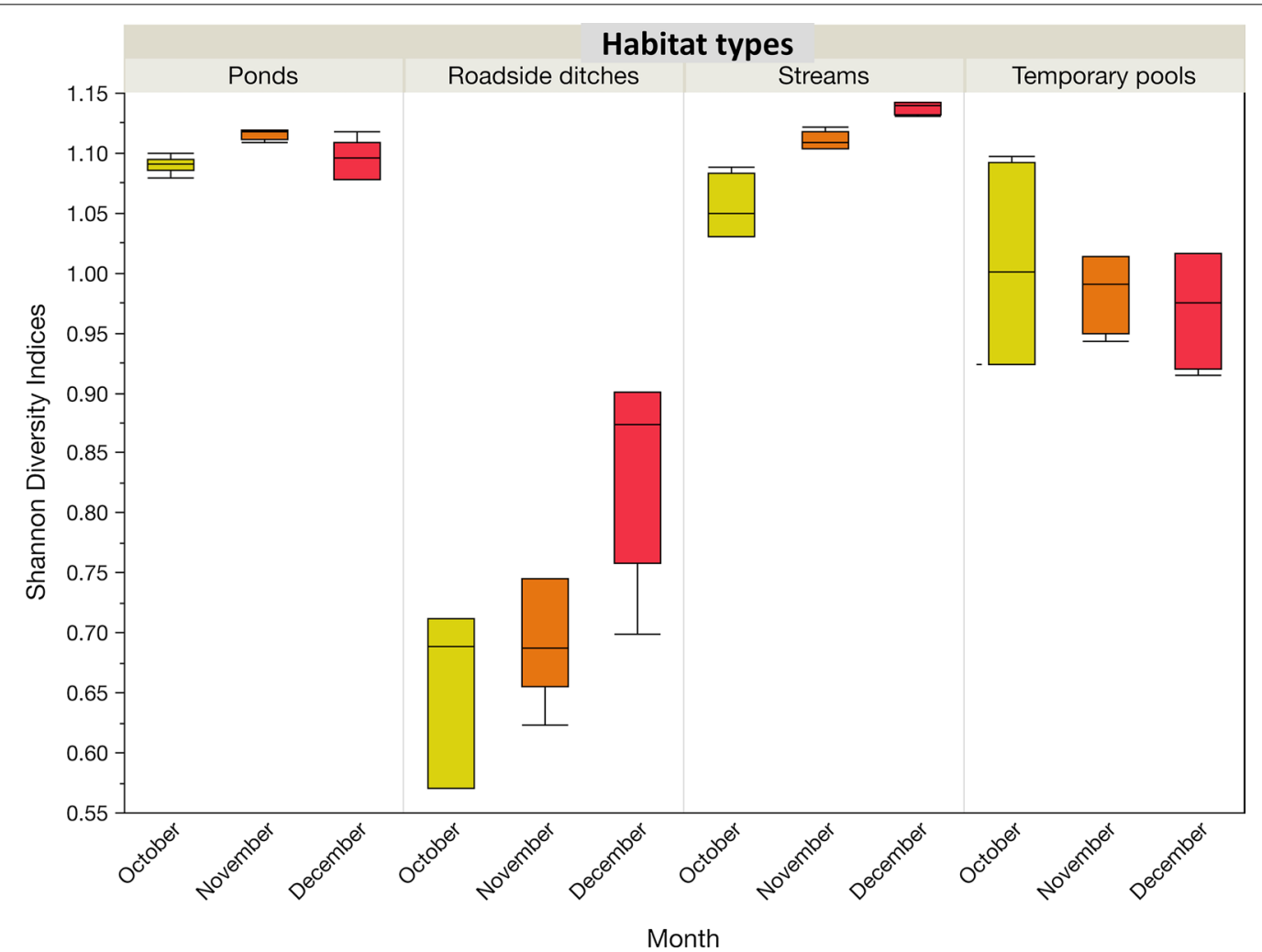

Fig. 6 Variation in diversity indices $\left(\mathrm{H}^{\prime}\right)$ of aquatic insect taxa across larval habitats (streams, temporary pools, ponds and roadside ditches) and months 


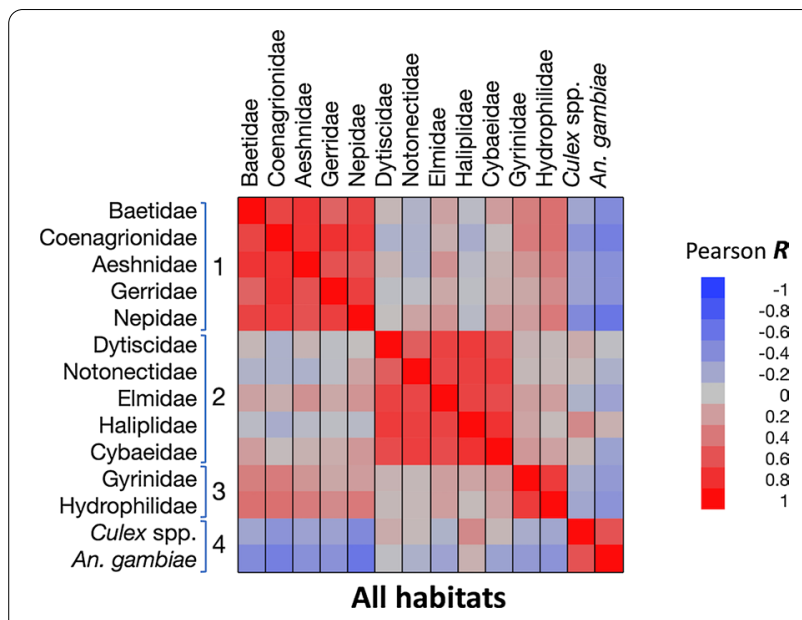

Fig. 7 Correlation clustering analysis of the overall habitats based on Pearson pairwise correlation pairwise correlations resulted in five clusters and 71.3\% of the variance explained, an average of $72.0 \%( \pm 7.4 \mathrm{SD})$ cluster variance explained, and a mean $0.353( \pm 0.157$ SD) $1-R^{2}$ ratio (Fig. 8a, Additional file 2: Table S3). Anopheles gambiae s.l. clustered with Dytiscidae, Cybaeidae and Elmidae. Culex spp. was assigned to a different cluster with Notonectidae (Fig. 8a, Additional file 2: Table S3).

In roadside ditches, An. gambiae s.l. abundance correlated significantly with Dytiscidae, and there was a weak significant negative correlation with Baetidae (Additional file 2: Table S2). The clustering of correlations was not as pronounced, and accounted for only $60 \%$ of the variation explained and four clusters (cluster variance $67.9 \% \pm 24$ SD and $0.412 \pm 0.307 \mathrm{SD}$ ). In that habitat, An. gambiae s.l. was grouped again with Dytiscidae and Cybaeidae,
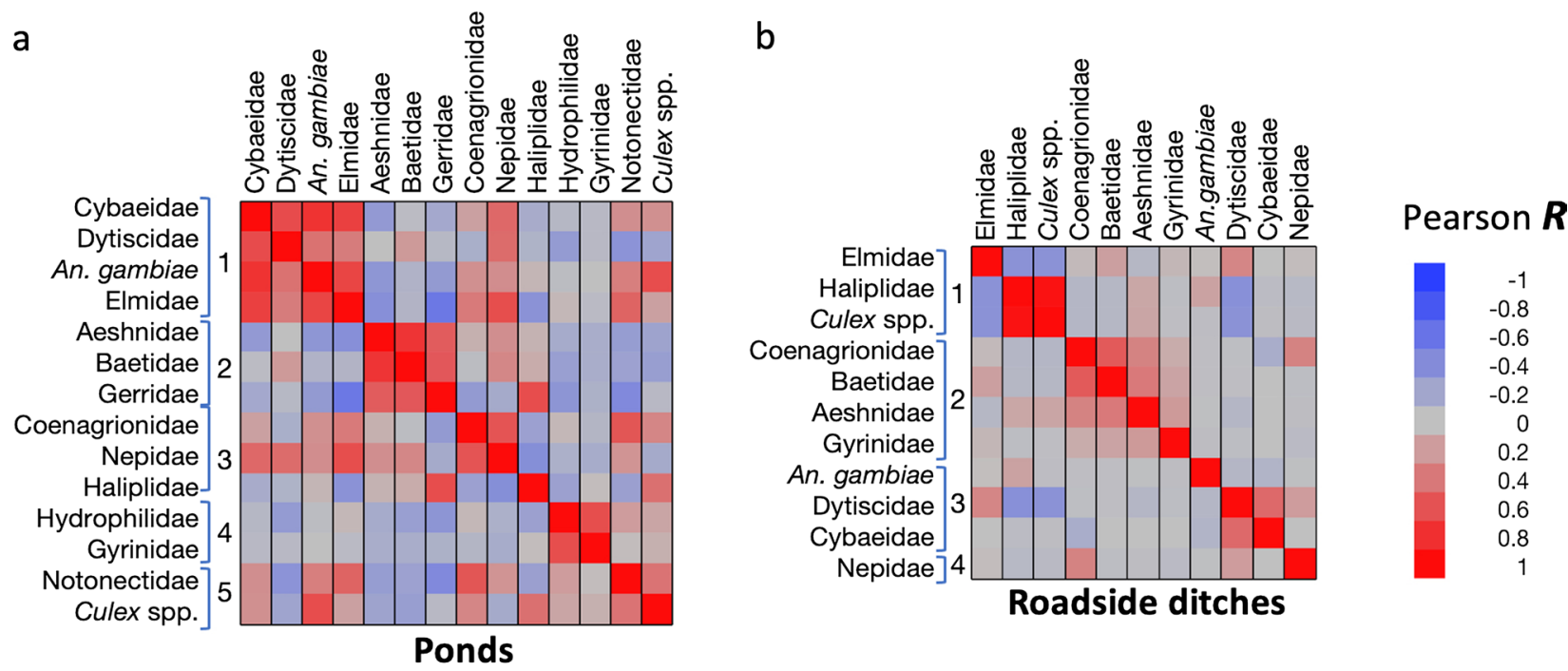

C
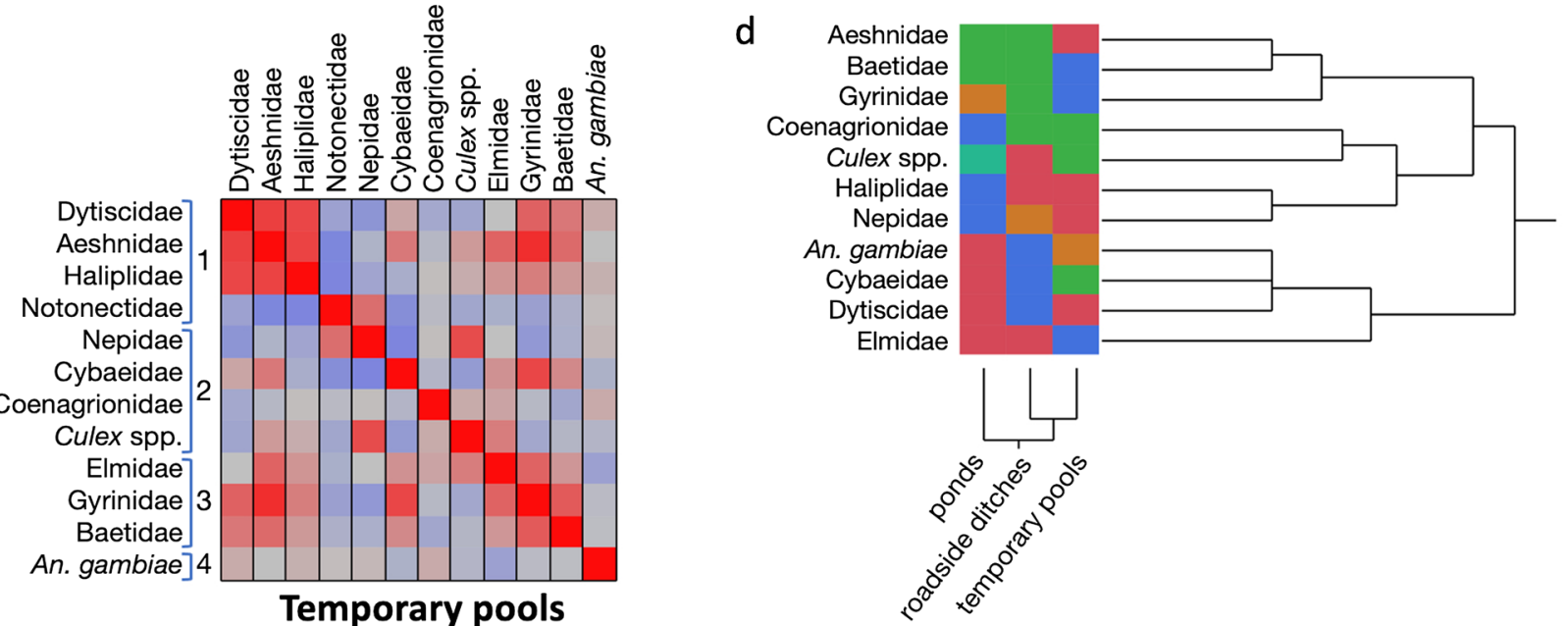

Temporary pools

Fig. 8 Correlation clustering analyses for ponds (a), roadside ditches (b) temporary pools (c) and the three habitat types combined (d) 
while Culex spp. were grouped with Elmidae and Haliplidae (Fig. 8b, Additional file 2: Table S3).

In temporary pools, clustering explained $62.3 \%$ of variation, four clusters (cluster variance $69.5 \% \pm 21.7 \mathrm{SD}$ and $0.453 \pm 0.262 \mathrm{SD}$ ). In temporary pools, An. gambiae s.l's microhabitat use did not cluster with any of the other taxa. Its abundance did not correlate significantly with other taxa except for a weak negative correlation with Baetidae (Fig. 8c, Additional file 2: Tables S3 and S4). Finally, a two-way higher-level hierarchical clustering analysis based on the cluster membership generated by the three cluster correlation analyses for each habitat type confirmed that the two taxa whose use of aquatic microhabitats most closely matched that of An. gambiae s.l. were Cybaeidae and Dytiscidae (Fig. 8d).

For these two taxa and Culex spp., the level of association between their presence and absence across all quadrats from the two habitats preferred by An. gambiae s.l. (roadside ditches and temporary pools) was also tested. Overall, Dytiscidae co-occurred with An. gambiae s.l. in $73.1 \%$ of quadrats, and their presence/absence were significantly associated (Chi-square likelihood ratio test: $X^{2}$ $=24.6, P<0.615)$. In contrast, Cybaeidae co-occurred with An. gambiae s.l. only in $5.7 \%$ of microhabitats, and their presence/absence was not significantly negatively associated (Chi-square likelihood ratio: $X^{2}=0.56$, $P=0.456$ ). It is noteworthy that while the cluster correlation analyses did not reveal a strong similarity in correlation profiles of An. gambiae s.l. and Culex spp., the two taxa co-occurred in $67.1 \%$ of the quadrats sampled, and they were more likely to occur together than by chance (Chi-square likelihood ratio: $X^{2}=23.1, P<0.001$ ).

\section{Discussion}

Kibuye and Kayonjo are among the most malaria-prone villages in central Uganda due to the high abundance of An. gambiae s.l. [37, 47]. These villages are areas of intense malaria transmission, hence the focus for an investigation on the ecology of An. gambiae s.l. breeding habitats. The results provide the first account of the diversity and abundance of potential predators (aquatic insects that prey upon An. gambiae s.l. larvae) and competitors (other mosquito genera which share the same food item) of An. gambiae s.l. larvae in the different aquatic habitats in Uganda.

In this study, roadside ditches had the highest mean temperature, $\mathrm{pH}$, EC and TDS, followed by intermediate values for temporary pools, with ponds and streams having the lowest parameter values. The prevailing water physico-chemical parameters of aquatic habitats influenced the insect taxa's distribution and abundance, including An. gambiae s.l. [48]. This study clearly shows that An. gambiae s.l. preferred temporary pools followed by roadside ditches, two habitats frequently shared with Culicinae mosquito larvae. These habitats were sometimes also used by various arthropod macroinvertebrates such as Dytiscidae, Nepidae, Notonectidae, Haliplidae, Elmidae, Baetidae and Cybaeidae. Previous studies have also reported that anopheline larvae often coexist with other macroinvertebrate predators [27, 49]. It has been suggested that An. gambiae s.l. larvae employ adaptive anti-predatory diving behaviour when sharing breeding habitats with aquatic predators [50]. Ponds had very few An. gambiae s.l. larvae, but very high numbers of Dytiscidae and Notonectidae. On the other hand, streams contained almost no An. gambiae s.l. larvae, but very high numbers of Baetidae, Coenagrionidae and Aeshnidae. In this study, we used a random sampling approach which, unavoidably, led to some quadrats being harder to sample with the standard dipper. In addition, habitats such as ponds and streams often had emergent vegetation that could have been used as a refuge by some macroinvertebrate taxa during sampling. This could have caused some bias in the habitat taxa profile reported in this study. However, we were highly confident that the large number of quadrats sampled per habitat ensured that major differences in taxa abundance and diversity were adequately detected.

The fact that An. gambiae s.l. larvae were common in temporary habitats and absent from permanent ones suggests that An. gambiae s.l. might have evolved to use temporal larval habitats to avoid predation and competition. Indeed, susceptibility to predation is one of the main forces structuring species communities among aquatic habitats [51]. The study has also shown that temporary pool breeding habitats and roadside ditches were the warmest and are therefore particularly suited for short multiple generation cycles such as that of mosquitoes.

Variation in the abundance and diversity of some aquatic insect taxa across habitat types and months was also largely associated with water persistence in each habitat type. High numbers of Gyrinidae and Hydrophilidae were found in the ponds during the start and peak of the short rainy season in October and November. High numbers of Baetidae were found at the end of the rainy season in December. This was probably due to water persisting in this habitat well beyond the entire sampling period and possibly for the better part of the year. The permanence of ponds can explain the highest diversity of insect taxa found in this habitat compared to streams, temporary pools and roadside ditches, a pattern that has been highlighted in other studies [21, 52-54].

The increase in numbers of Aeshnidae, Baetidae, Coenagrionidae and Nepidae in roadside ditches from the start to the end of the rainy season suggest that, even in such ephemeral habitats, water was present long enough 
for some taxa to possibly sustain a new generation and increase in numbers [55]. The nymphs of some Baetidae can complete their life cycle and emerge within a few weeks to contribute to the next generation, which will lay new eggs into the rain-filled breeding habitats. Other taxa, such as Aeshnidae, Coenagrionidae and Nepidae, have slower development, and their larvae must survive through the repeated wet and dry cycles of semipermanent and temporal aquatic habitats [56, 57]. For these species, the seasonal increase in numbers within the short rainy season suggests that semi-permanent and temporal aquatic habitats may be visited by adults who emerged from more permanent aquatic habitats or survived the dry season, waiting for the next rainy season to reproduce. For such species, laying eggs in more ephemeral habitats may be part of an oviposition bet-hedging strategy that creates opportunities for some offspring to develop in environments with lower-level competition and predation from other aquatic predators than in ponds.

Interestingly, we found a few larvae of An. gambiae s.l. in streams in November, following an interruption in rainfall, which resulted in the creation of sun-exposed puddle-like habitats suitable for An. gambiae s.l. [58]. In those puddle-like habitats, An. gambiae s.l. larvae were often found with Hydrophilidae, which mainly breed in permanent water bodies [59]. The An. gambiae s.l. larvae may have been trapped in these temporarily created breeding habitats. Such a rain pattern could also explain the appearance of Cybaeidae, Gyrinidae and Haliplidae towards the end of the short rainy season in streams.

Across all habitats, the abundance of An. gambiae s.l. gave a significantly positive correlation with the Culex spp. This can largely be explained by the fact that both mosquito taxa prefer roadside ditches and temporary pools over ponds and streams. Despite this apparent niche overlap, there were differences between the two taxa. Notably, Culex spp. was regularly found in streams, where An. gambiae s.l. is extremely rare. It was also more common in ponds and less frequent in roadside ditches compared to An. gambiae s.l. Thus, there is only partial niche overlap between these taxa in terms of habitat preferences.

This study pushed the analyses further by clustering all pairwise correlations among aquatic invertebrates to identify those whose patterns of abundance in samples from different microhabitats/quadrats most closely matched. This approach, applied to all quadrats from all habitats, generally grouped taxa whose abundance and breeding site preferences correlated broadly across all habitats. In this instance, An. gambiae s.l. and Culex spp. clustered together. However, the congruence between both analytical approaches stopped when conducted within habitat type, the spatial scale most likely to highlight predators and competitors that might interact with An. gambiae s.l. In ponds, An. gambiae s.l. abundance showed a moderate positive correlation with Dytiscidae, Cybaeidae, Coenagrionidae, Nepidae, Elmidae and Culex spp., but a significant negative correlation with other taxa except Hydrophilidae and Aeshnidae. The cluster correlation analyses grouped An. gambiae s.l. with Dytiscidae, Cybaeidae and Elmidae, suggesting that these tend to be captured within the same microhabitats within ponds, and in this particular instance, the herbaceous margins of ponds. Culex spp. were grouped into a separate cluster with Notonectidae, a taxon that prefers deeper water further from the ponds' edges. Overall, the cluster correlation analyses underlined the pond's heterogeneity, with different microhabitats populated by different assemblages of aquatic invertebrate taxa. The same analyses conducted on the data from roadside ditches and temporary rain pools again showed that the microhabitat usage by An. gambiae s.l. was most similar to Dytiscidae and Cybaeidae. Culex spp. was less frequent than An. gambiae s.l. in such habitats, and it did not cluster with An. gambiae s.l., suggesting again that it uses different areas of the aquatic habitats. Culex spp. are known to prefer habitats richer in organic matter, and An. gambiae s.l. cleaner water. Ecological niche partitioning may thus explain why, despite their similar life cycle, the two mosquito taxa did not cluster together [60]. It should be noted that, whilst Culex quinquefasciatus is usually the dominant species in domestic and peridomestic settings [61], we cannot dismiss the possibility that some of the sylvatic Culex spp. found in Uganda were also present in our samples $[62,63]$.

Thus, the overall patterns of temporal and spatial dynamics of An. gambiae s.l. larvae and other aquatic invertebrates suggest that Dytiscidae and, in some microhabitats, Cybaeidae could be important predators of $A n$. gambiae s.l. This is based on the assumption that if two taxa compete or interact as prey and predator, they are expected to be found together in breeding habitats [6466]. Moreover, it further assumes that, as in other predator-prey systems, aquatic invertebrate predators do not wipe out their prey completely, resulting in predator and prey abundance being positively correlated [67]. Nevertheless, because the data are based on observations and correlational analyses, further studies are needed to test the strength of these interactions experimentally. Also, although we were able to generate a substantial amount of information from the data collected during the short rainy season of October-December, the dynamics taking place during the rest of the year and particularly during the other rainy season of March-May remains to be unraveled. This was the limitation of this study. 
In our samples, $80 \%$ of the Dytiscidae belonged to the genus Cybister, and the remaining samples were from the genus Rhantus. Over $70 \%$ of individuals had reached adult stages, and 30\% were larvae. The potential use of Dytiscidae for mosquito control has been examined in experiments focusing on two Asian Dytiscidae species $[68,69]$. These studies demonstrated that water beetles are very effective predators and can consume dozens of mosquito larvae per day. Additionally, adult Dytiscidae are good fliers and can easily find new habitats. Furthermore, their larvae have a fast developmental rate, can undergo metamorphosis and remain dormant in the mud of dried-up temporary larval habitats till the next rains. These traits make water beetles particularly adapted to the preferred habitats of An. gambiae s.l. The Cybaeidae are much less frequent than Dytiscidae but share the shallow herbaceous margins of ponds and temporary pools with $A n$. gambiae s.l. larvae. Cluster correlation analyses highlighted this similarity of microhabitat usage, giving confidence in the sampling and analytical approach of the study. In retrospect, it would be recommended that when a similar sampling approach is used, microhabitats/quadrats could be further characterized in terms of water depth, distance from the water edge and aquatic vegetation, which are likely important predictors of the aquatic arthropod communities. While unable to fly, Cybaeidae are thought to reach new habitats via the dispersal of juveniles which are thought to use silk threads to catch the wind [70,71]. Given the narrower set of conditions in which this taxon was found in numbers alongside An. gambiae s.l., and taking into account their complex life cycle, it has less potential for biocontrol developments.

\section{Conclusions}

Mosquito breeding habitats such as streams, ponds, roadside ditches and temporary pools differed in water physico-chemical parameters (temperature, $\mathrm{pH}$, TDS and EC). They differed in the abundance and diversity of macroinvertebrate predators and competitor insect taxa and how these are associated with An. gambiae s.l. larvae. Ponds and streams were the most preferred breeding habitats for most predators and competitors, while temporary pools and roadside ditches were preferred by An. gambiae s.l. larvae. In these habitats, there were partial niche overlaps between An. gambiae s.l. larvae and Culex spp., but there was no evidence of competition between the two taxa. Overall, the predators that most closely shared An. gambiae s.l's temporal and spatial dynamics across and within An. gambiae s.l. larval habitats were Dytiscidae and, in some microhabitats, Cybaeidae. The strength of these prey-predator relationships and their potential for mosquito larvae's biocontrol in the African setting remains to be demonstrated through controlled experimental studies. Also, we recommend further studies using a similar method for over 1-2 years. This would allow for a reflection of information variations across seasons.

\section{Abbreviations \\ s.l.: Sensu lato; TDS: Total dissolved solids; EC: Electrical conductivity; s.s.: Sensu stricto; pH: Potential hydrogen; LVB: Lake Victoria Basin; PCA: Principal component analysis.}

\section{Supplementary Information}

The online version contains supplementary material available at https://doi. org/10.1186/s13071-021-04926-9.

Additional file1: Figure S1. Neighbour-joining cluster analyses based on (a) physico-chemical parameters and (b) aquatic insect taxa abundance of two quadrats from each of the 32 surveyed habitats. Samples from the two quadrats were collected one month apart (October-November). The tree based on chemical parameters had much shallower distal branches, and several pairs of quadrats from the same breeding habitat were nearest neighbours (highlighted). In comparison, the tree based on species abundance had deeper distal branching, and none of the quadrats sampled from the same habitat was nearest neighbours.

Additional file 2: Table S1. Mean and median abundance, diversity and percentage frequency of aquatic insect taxa across habitat types in Kibuye. Table S2. Mean and median abundance, diversity and percentage frequency of aquatic insect taxa across habitat types in Kayonjo. Table S3. Pairwise correlations between the abundance of Anopheles gambiae sensu lato larvae and the abundance of aquatic predators and competitors across all habitats and for each habitat type. Table S4. Cluster membership based on heat map analyses for the correlations across all habitats and for each habitat type.

\section{Acknowledgements}

The authors wish to thank the staff of the Department of Entomology, Uganda Virus Research Institute, Entebbe, and the staff of the Department of Zoology, Entomology and Fisheries Sciences, Makerere University, for their support at various stages of this work. Finally, we thank Carol Stimpson and Nwamaka Akopdiete for their comments on the manuscript.

\section{Authors' contributions}

$\mathrm{HO}$ collected and analysed the data and wrote the manuscript. RO supervised the study and guided the writing of the manuscript. MC supervised the study, guided the writing of the manuscript and advised on the initial stage of the data analysis. FT analysed the data and guided the writing process of the manuscript. JKK generated the research idea and supervised the study. All authors proofread the manuscript.

\section{Funding}

This study was funded by Target Malaria, which receives core funding from the Bill \& Melinda Gates Foundation, Open Philanthropy Project Fund, an advised fund of the Silicon Valley Community Foundation, and DELTAS Africa Initiative grant \# DEL-15-011 to THRiVE-2.

Availability of data and materials

The data is available upon request to the corresponding authors.

\section{Declarations}

Ethics approval and consent to participate Not applicable. 


\section{Consent for publication \\ Not applicable.}

\section{Competing interests}

The authors declare that they have no competing interests.

\section{Author details}

1 Department of Zoology, Entomology and Fisheries Sciences, College of Natural Sciences, School of Biosciences, Makerere University, PO Box 7062, Kampala, Uganda. ${ }^{2}$ Department of Entomology, Uganda Virus Research Institute (UVRI), PO Box 49, Entebbe, Uganda. ${ }^{3}$ Centre for Applied Entomology and Parasitology, School of Life Sciences, Keele University, Keele, SFD ST5 5BG, UK.

Received: 23 March 2021 Accepted: 4 August 2021

Published online: 21 August 2021

\section{References}

1. WHO. World malaria report. World Health Organization, Geneva. 2020.

2. de Souza D, Kelly-Hope L, Lawson B, Wilson M, Boakye D. Environmental factors associated with the distribution of Anopheles gambiae s.s in Ghana; an important vector of lymphatic filariasis and malaria. PLoS ONE. 2010;5:e9927.

3. Parham PE, Pople D, Christiansen-Jucht C, Lindsay S, Hinsley W, Michael E. Modeling the role of environmental variables on the population dynamics of the malaria vector Anopheles gambiae sensu stricto. Malar J. 2012:11:271.

4. Kisinza WN, Nkya TE, Kabula B, Overgaard HJ, Massue DJ, Mageni Z, et al. Multiple insecticide resistance in Anopheles gambiae from Tanzania : a major concern for malaria vector control. Malar J. 2017:16:439.

5. Dabiré RK, Namountougou M, Sawadogo SP, Yaro LB, Toé HK, Ouari A, et al. Population dynamics of Anopheles gambiae s.l. in Bobo-Dioulasso city: bionomics, infection rate and susceptibility to insecticides. Parasit Vectors. 2012;5:127.

6. Sherrard-Smith E, Skarp JE, Beale AD, Fornadel C, Norris LC, Moore SJ, et al. Mosquito feeding behavior and how it influences residual malaria transmission across Africa. Proc Natl Acad Sci U S A. 2019;116:15086-96.

7. Tusting LS. Larval source management: a supplementary measure for malaria control. Outlooks Pest Manag. 2014;25:41-3.

8. Eba K, Duchateau L, Olkeba BK, Boets P, Bedada D, Goethals PLM, et al. Bio-control of Anopheles mosquito larvae using invertebrate predators to support human health programs in Ethiopia. Int J Environ Res Public Health. 2021:18:1810.

9. Shaalan EAS, Canyon DV. Aquatic insect predators and mosquito control. Trop Biomed. 2009;26:223-61.

10. Collins CM, Bonds JAS, Quinlan MM, Mumford JD. Effects of the removal or reduction in density of the malaria mosquito, Anopheles gambiae s.l., on interacting predators and competitors in local ecosystems. Med Vet Entomol. 2019;33:1-15.

11. Tchouassi DP, Quakyi IA, Addison EA, Bosompem KM, Wilson MD, Appawu $M A$, et al. Characterization of malaria transmission by vector populations for improved interventions during the dry season in the Kpone-on-sea area of coastal Ghana. Parasit Vectors. 2012;5:212

12. Coetzee M, Hunt RH, Wilkerson R, Della Torre A, Coulibaly MB, Besansky NJ. Anopheles coluzzii and Anopheles amharicus, new members of the Anopheles gambiae complex. Zootaxa. 2013;3619:246-74.

13. Sinka ME. Global distribution of the dominant vector species of malaria. UK: Intechopen; 2018. p. 1-37. http://dx.doi.org/10.5772/54163

14. Barrón MG, Paupy C, Rahola N, Akone-Ella O, Ngangue MF, Wilson-Bahun TA, et al. A new species in the major malaria vector complex sheds light on reticulated species evolution. Sci Rep. 2019;9:14753.

15. Sharower MG, Latif MA, Uddin SM. Temporal distribution and abundance of mosquito vectors in Dhaka city. J Asiat Soc Bangladesh Sci. 2020;46:27-35.

16. White GB. Anopheles bwambae sp.n., a malaria vector in the Semliki Valley, Uganda, and its relationships with other sibling species of the An. gambiae complex (Diptera: Culicidae). Syst Entomol. 1985;10:501-22.

17. Sinka ME, Bangs MJ, Manguin S, Coetzee M, Mbogo CM, Hemingway J, et al. The dominant Anopheles vectors of human malaria in Africa, Europe and the Middle east: occurrence data, distribution maps and bionomic précis. Parasit Vectors. 2010;3:117.

18. Edillo FE, Touré YT, Lanzaro GC, Dolo G, Taylor CE. Spatial and habitat distribution of Anopheles gambiae and Anopheles arabiensis (Diptera: Culicidae) in Banambani Village. Mali J Med Entomol. 2002;39:70-7.

19. Gimonneau G, Pombi M, Choisy M, Morand S, Dabiré RK, Simard F. Larval habitat segregation between the molecular forms of the mosquito Anopheles gambiae in a rice field area of Burkina Faso, West Africa. Med Vet Entomol. 2012;26:9-17.

20. Dida GO, Gelder FB, Anyona DN, Abuom PO, Onyuka JO, Matano AS, et al. Presence and distribution of mosquito larvae predators and factors influencing their abundance along the Mara River, Kenya and Tanzania. Springerplus. 2015;4:136.

21. Banerjee S, Aditya G, Saha N, Saha GK. An assessment of macroinvertebrate assemblages in mosquito larval habitats-space and diversity relationship. Environ Monit Assess. 2009;168:597-611.

22. Ong'Wen F, Onyango PO, Bukhari T. Direct and indirect effects of predation and parasitism on the Anopheles gambiae mosquito. Parasit Vectors. 2020;13:43

23. Roux O, Vantaux A, Roche B, Yameogo KB, Dabiré KR, Diabaté A, et al. Evidence for carry-over effects of predator exposure on pathogen transmission potential. Proc R Soc B Biol Sci. 2015;282:20152430.

24. Munga S, Minakawa N, Zhou G, Barrack O-OJ, Githeko AK, Yan G. Effects of larval competitors and predators on oviposition site selection of Anopheles gambiae sensu tricto. J Med Entomol. 2006;43:221-4.

25. Warburg A, Faiman R, Shtern A, Silberbush A, Markman S, Cohen JE, et al. Oviposition habitat selection by Anopheles gambiae in response to chemical cues by Notonecta maculata. J Vector Ecol. 2011;36:421-5.

26. Herrera-Varela M, Lindh J, Lindsay SW, Fillinger U. Habitat discrimination by gravid Anopheles gambiae sensu lato-a push-pull system. Malar J. 2014;13:133.

27. Minakawa N, Mutero CM, Githure Jl, Beier JC, Yan G. Spatial distribution and habitat characterization of anopheline mosquito larvae in western Kenya. Am J Trop Med Hyg. 1999;61:1010-10106.

28. Ndenga BA, Simbauni JA, Mbugi JP, Githeko AK, Fillinger U. Productivity of malaria vectors from different habitat types in the western Kenya highlands. PLoS ONE. 2011;6:e19473.

29. Musiime AK, Smith DL, Kilama M, Geoffrey O, Kyagamba P, Rek J, et al. Identification and characterization of immature Anopheles and culicines (Diptera: Culicidae) at three sites of varying malaria transmission intensities in Uganda. Malar J. 2020;19:221.

30. Dida GO, Anyona DN, Abuom PO, Akoko D, Adoka SO, Matano A, et al. Spatial distribution and habitat characterization of mosquito species during the dry season along the Mara River and its tributaries, in Kenya and Tanzania. Infect Dis Poverty. 2018;18(7):2.

31. Emidi B, Kisinza WN, Mmbando BP, Malima R, Mosha FW. Effect of physico-chemical parameters on Anopheles and Culex mosquito larvae abundance in different breeding sites in a rural setting of Muheza, Tanzania. Parasit Vectors. 2017:10:304.

32. Chen H, Githeko AK, Zhou G, Githure JI, Yan G. New records of Anopheles arabiensis breeding on the Mount Kenya highlands indicate indigenous malaria transmission. Malar J. 2006;5:17.

33. Ogola EO, Odero JO, Mwangangi JM, Masiga DK, Tchouassi DP. Population genetics of Anopheles funestus, the African malaria vector, Kenya. Parasit Vectors. 2019:12:15

34. Temu EA, Minjas JN, Coetzee M, Hunt RH, Shiff CJ. The role of four anopheline species (Diptera: Culicidae) in malaria transmission in coastal Tanzania. Trans R Soc Trop Med Hyg. 1998;92:152-8.

35. Onen $\mathrm{H}$, Odong $\mathrm{R}$, Chemurot M, Kayondo J. Biotic and abiotic factors in Anopheles gambiae breeding habitats as a potential tool to fight malaria in Central Uganda. J Dis Glob Heal. 2019;12:12-20.

36. Nambunga IH, Ngowo HS, Mapua SA, Hape EE, Msugupakulya BJ, Msaky DS, et al. Aquatic habitats of the malaria vector Anopheles funestus in rural south-eastern Tanzania. Malar J. 2020:19:219.

37. Kabbale FG, Anne MA, John BK, Enock M, Anne K, Anges Y, et al. Molecular identification of Anopheles gambiae sensu stricto Giles (formerly Anopheles gambiae Savannah Form) in Kamuli district, Uganda. Afr J Biotechnol. 2016;15:39.

38. Kang SY, Battle KE, Gibson HS, Cooper LV, Maxwell K, Kamya M, et al. Heterogeneous exposure and hotspots for malaria vectors at three study sites in Uganda. Gates Open Res. 2018;13:32. 
39. UBOS. Uganda bureau of statistic: The national population and housing census 2014- Main report, Kampala, Uganda. Uganda Bur Stats. 2016;50-80. www.ubos.org. Accessed 17 Mar 2021.

40. Anon. Kayunga 3-year district development plan 2010-2013. 2010. https://kayunga.go.ug.

41. UNMA. Uganda national meteorological authority. 2016. p. 1-7. wWW unma.go.ug. Accessed 17 Mar 2021.

42. Gerber A, Gabriel MJM. Aquatic invertebrates of South African Rivers Field Guide. 2002. p. 1-78.

43. Gill K. Identification guide to freshwater macro-invertebrates. 2015. p. $1-6$.

44. Hopkins GHE. Mosquitoes of the Ethiopian region I. Larval bionomics of mosquitoes and taxonomy of culicine larvae. 2nd ed. London: British museum (Natural history); 1952.

45. Rozeboom LE, Stone A. Keys to the anopheline mosquitoes of the world with notes on their identification, distribution, biology, and relation to malaria. J Am Med Assoc. 1945;128:551.

46. Shannon CE, Weaver W. The mathematical theory of communication. Bell Syst Tech J. 1948;27:379-423.

47. Mbonye AK, Bygbjerg IC, Magnussen P. Prevention and treatment practices and implications for malaria control in Mukono district Uganda. J Biosoc Sci. 2008:40:283-96.

48. Mereta ST, Yewhalaw D, Boets P, Ahmed A, Duchateau L, Speybroeck N, et al. Physico-chemical and biological characterization of anopheline mosquito larval habitats (Diptera: Culicidae): implications for malaria control. Parasit Vectors. 2013;6:320

49. Ohba SY, Kawada H, Dida GO, Juma D, Sonye G, Minakawa N, et al. Predators of Anopheles gambiae sensu lato (Diptera: Culicidae) larvae in wetlands, western Kenya: Confirmation by polymerase chain reaction method. J Med Entomol. 2010;47:783-7.

50. Futami K, Sonye G, Akweywa P, Kaneko S, Minakawa N. Diving behavior in Anopheles gambiae (Diptera: Culicidae): Avoidance of a predacious wolf spider (Araneae: Lycosidae) in relation to life stage and water depth. J Med Entomol. 2008:45:1050-6.

51. Wellborn GA, Skelly DK, Werner EE. Mechanisms creating community structure across a freshwater habitat gradient. Annu Rev Ecol Syst. 1996:27:337-63.

52. Collinson NH, Biggs J, Corfield A, Hodson MJ, Walker D, Whitfield M, et al. Temporary and permanent ponds: an assessment of the effects of drying out on the conservation value of aquatic macroinvertebrate communities. Biol Conserv. 1995;74:125-33.

53. Svitok M, Novikmec M, Ocadlik M. Local, among-site, and regional diversity patterns of benthic macroinvertebrates in high altitude water bodies : do ponds differ from lakes? Hydrobiologia. 2014;273:41-52.

54. Williams P, Whitfield M, Biggs J, Bray S, Fox G, Nicolet P, et al. Comparative biodiversity of rivers, streams, ditches and ponds in an agricultural landscape in southern England. Biol Conserv. 2004;115:329-41.

55. Porst G, Naughton O, Gill L, Johnston P, Irvine K. Adaptation, phenology and disturbance of macroinvertebrates in temporary water bodies. Zootaxa. 2012;696:47-62.
56. Corbet PS. The life-history of the emperor dragonfly Anax imperator Leach (Odonata: Aeshnidae). J Anim Ecol. 1957;26:1-69.

57. Nolte U, Tietböhl RS, Mccafferty WP. A mayfly from tropical Brazil capable of tolerating short-term dehydration. J North Am Benthol Soc. 1996;15:87-94.

58. Hamza AM, El REA. A qualitative evidence of the breeding sites of Anopheles arabiensis patton (Diptera: Culicidae) in and around Kassala town, eastern Sudan. Int J Insect Sci. 2016;8:65-70.

59. Chirebvu E, Chimbari MJ. Characteristics of Anopheles arabiensis larval habitats in Tubu village, Botswana. J Vector Ecol. 2015;40:129-38.

60. Gilbreath TM, Kweka EJ, Afrane YA, Githeko AK, Yan G. Evaluating larval mosquito resource partitioning in western Kenya using stable isotopes of carbon and nitrogen. Parasit Vectors. 2013;6:353.

61. Bhattacharya S, Basu P, Sajal BC. The southern house mosquito, Culex quinquefasciatus: profile of a smart vector. J Entomol Zool Stud JEZS. 2016:4:73-81.

62. Mayanja M, Mutebi J-P, Crabtree MB, Ssenfuka F, Muwawu T, Lutwama JJ. Abundance of mosquitoes of Mpigi district, central Uganda. J Entomol Zool Stud. 2014;2:317-22.

63. Mutebi J-P, Crabtree MB, Crockett RJK, Powers AM, Lutwama JJ, Miller BR. Mosquitoes of western Uganda. J Med Entomol. 2012;49:1289-306.

64. Bastille-Rousseau G, Rayl ND, Ellington EH, Schaefer JA, Peers MJL, Mumma MA, et al. Temporal variation in habitat use, co-occurrence, and risk among generalist predators and a shared prey. Can J Zool. 2016:94:191-8.

65. Hartman R, Pope K, Lawler S. Factors mediating co-occurrence of an economically valuable introduced fish and its native frog prey. Conserv Biol. 2013;28:763-72.

66. Léandri-Breton DJ, Bêty J. Vulnerability to predation may affect species distribution: plovers with broader arctic breeding range nest in safer habitat. Sci Rep. 2020;10:5032

67. Millon A, Nielsen JT, Bretagnolle V, Møller AP. Predator-prey relationships in a changing environment: the case of the sparrowhawk and its avian prey community in a rural area. J Anim Ecol. 2009;78:1086-95.

68. Aditya G, Ash A, Saha GK. Predatory activity of Rhantus sikkimensis and larvae of Toxorhynchites splendens on mosquito larvae in Darjeeling. India J Vector Borne Dis. 2006:43:66-72.

69. Chandra G, Mandal SK, Ghosh AK, Das D. Biocontrol of larval mosquitoes by Acilius sulcatus (Coleoptera : Dytiscidae). BMC Infect Dis. 2008;8:138.

70. Masumoto T, Masumoto T, Yoshida M, Nishikawa Y. Water conditions of the habitat of the water spider Argyroneta aquatica (Araneae: Argyronetidae) in Mizoro pond. Acta Arachnol. 1998;47:121-4.

71. Schütz D, Taborsky M. Adaptations to an aquatic life may be responsible for the reversed sexual size dimorphism in the water spider Argyroneta aquatica. Evol Ecol Res. 2003;5:105-17.

\section{Publisher's Note}

Springer Nature remains neutral with regard to jurisdictional claims in published maps and institutional affiliations.
Ready to submit your research? Choose BMC and benefit from:

- fast, convenient online submission

- thorough peer review by experienced researchers in your field

- rapid publication on acceptance

- support for research data, including large and complex data types

- gold Open Access which fosters wider collaboration and increased citations

- maximum visibility for your research: over $100 \mathrm{M}$ website views per year

At BMC, research is always in progress.

Learn more biomedcentral.com/submissions 